\title{
Expanding the evidence on cancer screening: the value of scientific, social and ethical perspectives
}

\section{Lucie Rychetnik \\ $\mathrm{BSc}, \mathrm{MPH}, \mathrm{PhD}$, \\ Senior Research Fellow, \\ Screening and Test \\ Evaluation Program, \\ School of Public Health}

Stacy M Carter BAppSci, MPH, PhD NHMRC Caree

Development Fellow, Centre for Values, Ethics and the Law in Medicine

Alexandra Barrat

MB BS, MPH, PhD, Professor

School of Public Health

Les Irwig

BSc, MB BCh, PhD,

Professor,

School of Public Health

University of Sydney,

Sydney, NSW.

lucie.rychetnik@

sydney.edu.au

doi: 10.5694/mjal2.11275 $\square$ xperts have called for more attention to the politics, communication and ethics of screening, but there has been limited guidance on how this should be done. In this article, we propose the need for an expanded evidence base for cancer screening policy and practice. This has significant implications for cancer screening research, and for the type of research that could then be considered in evidence reviews and summaries. This approach builds on two ideas previously raised but not yet fully explored in the medical literature. ${ }^{1,2}$ The first is that we need to better understand why screening happens the way it does, sometimes apparently at odds with evidence of benefits and harms. This requires thinking about screening as a social process involving interest groups, politics, markets, consumers and health professionals. The second is that we need to think more systematically about the ethics of screening. Decades of screening guidelines and research have involved implicit moral judgements, but these have rarely applied formal ethical theory or drawn on empirical ethics research. By applying ethical frameworks and theories to guide research on moral and ethical questions in cancer screening, we will be more able to make ethical judgements on cancer screening policies and practices. We argue that more explicit and systematic investigation of the social and ethical aspects of cancer screening can support better informed and more accountable policy and practice decisions.

\section{The value of formal inquiry into social and ethical aspects of screening}

While attention to the benefits, harms and costs of cancer screening is essential, it is often insufficient to guide cancer screening policy and practice; for example, on prostatespecific antigen (PSA) screening ${ }^{3}$ or mammography. ${ }^{4,5}$ An expanded approach will allow a more comprehensive understanding of the social and ethical implications of cancer screening that would rely on the generation and use of three kinds of evidence:

- Scientific evidence of the benefits, harms or costs of screening. This type of evidence is generally available albeit sometimes unclear, or conflicting and contested and already used in the development of screening policy and practice.

- Evidence about screening as a social activity, producing descriptions and explanations of how and why screening is done. This will require empirical research about social structures and processes, and consideration of screening provision in relation to evidence, societal values, and

\begin{abstract}
Summary
- We propose an expanded approach to evidence for cancer screening policy and practice.

- First, we need to better understand why and how screening happens the way it does, sometimes at odds with evidence of benefits and harms.

- Second, we need to systematically investigate the ethics of cancer screening to illuminate moral concerns and expand the scope of screening research to address ethical dilemmas.

- An expanded approach will offer essential information to better support well reasoned judgements, and develop more accountable and less contested cancer screening policies.
\end{abstract}

political and commercial interests. This type of evidence is currently limited and not generally used in the development of screening policy and practice.

- Evidence from empirical ethics research that is guided by formal ethical concepts and reasoning, and normative ethical frameworks to answer ethical questions about screening options. This type of evidence is currently very limited and is not used in the development of screening policy and practice.

These three types of evidence, and the knowledge and understanding that they generate, would mutually influence each other, as illustrated in Box 1.

\section{Investigating screening as a social issue}

Cancer screening is a complex social process, involving different people, organisations and technologies. Social research is valued in medicine and public health for its ability to answer questions about the way that things happen and what things mean. It generates knowledge about people, their interactions, and the way their actions can be explained in the context of social structures and situations. It examines accounts of individuals' experiences and perspectives on the world, and observes their actions, how they talk, and the way they use technologies and other material things. It can also examine and explain positions taken and the actions of groups such as social, professional or commercial entities. Interviews, focus groups, direct observations and existing documents (such as policies, websites or newspapers) can all provide data for research to determine how screening is currently occurring, why it is occurring in that way, and what is required to change how it occurs. 


\section{A threefold approach for evaluating cancer screening}

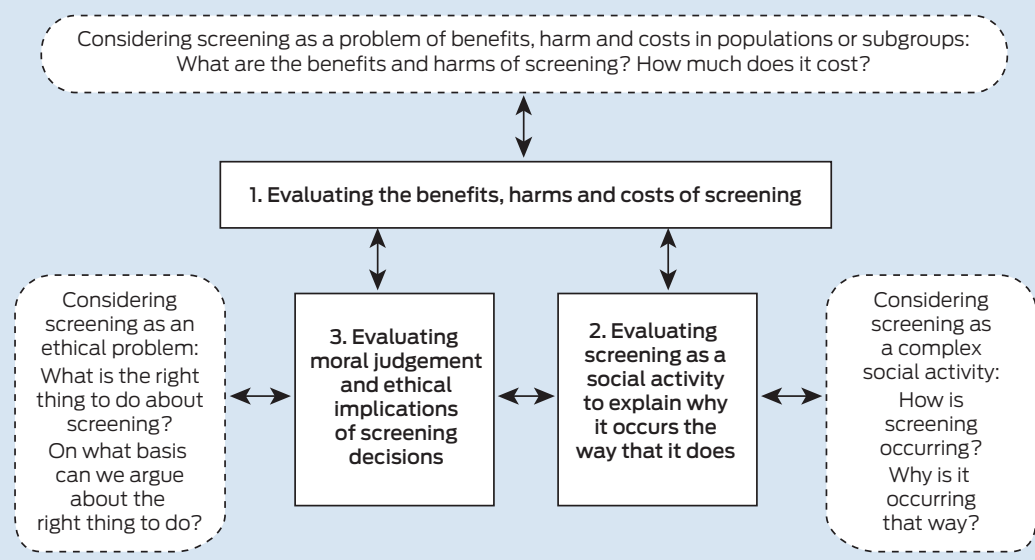

Research on how screening programs have developed would explain why implementation is variable, consistent or inconsistent with the evidence base, how screening providers make decisions in the context of uncertainty, and how conflicts have developed. Research on how screening programs are provided can also explain how and why consumers, providers, decisionmakers and commercial interests act in relation to screening. For example, why consumers overestimate screening benefits, how technologies can become entrenched in the absence of evidence, and how financial or institutional interests influence communication about screening. Fletcher has argued that population scientists need "to better communicate with the public if evidence-based recommendations [about screening] are to be heeded by clinicians, patients, and insurers". ${ }^{2}$ This can only be achieved through understanding the actions, influences and motivations of all interest groups, and this can be empirically derived and described through systematic and rigorous social research.

\section{Investigating screening as an ethical issue}

Ethics is the branch of philosophy focused on moral reasoning and determining right actions; it aims to discover the right thing to do, and to determine why it is right. A number of writers have considered the ethics of screening, but screening research has not routinely considered ethical questions. Formal application of ethical theory in designing screening research could provide frameworks to examine and explain existing moral concerns in screening; expand the scope of what is investigated by introducing concepts and theories to drive new cancer screening research; and make explicit the plurality of values in screening decisions and offer criteria to evaluate whether and how well this plurality has been addressed.

Ethics can provide new tools to address moral concerns that have been troubling screening experts for many decades. For example, Fletcher's analysis of breast cancer epidemiology, ${ }^{2}$ the proposal by Harris and colleagues that screening should be evaluated according to the umbrella concept of a "predictor of poor health", 1 or Eddy's costeffectiveness analysis decision tables ${ }^{6}$ all seek to answer a question with moral significance: how can we best maxim- ise the benefits and minimise the harms of intervention? This question is central in utilitarianism, which considers the best actions to be those that generate the greatest utility for the greatest number of people - where utility might be defined as pleasure, happiness or health, or more generically, benefit. The literature about the strengths and weaknesses of utilitarianism can inform how we study the benefits and harms of screening. Traditional approaches to screening have been critiqued as "naively utilitarian" ${ }^{7}$ for downplaying the moral significance of harming some to benefit others, and the consequences of service providers failing to disclose the possible harms of screening to recipients. Critiques of utilitarianism might also encourage further study of which benefits and harms count in a decision-making calculus, or the problems and implications of combining qualitatively different benefits and harms into a single metric. ${ }^{8}$

Other ethical theories emphasise different concerns, such as our moral duty to respect others, and how to balance concerns for individuals with concerns for communities. Such theories encourage explicit examination of the responsibilities of service providers towards screening candidates, empirical evaluation of the moral significance and impact of supporting (or not supporting) the autonomy of those screened, and whether there are any conditions under which mandatory screening might be considered acceptable.

\section{Three-dimensional evidence: examining PSA screening as a scientific, social and ethical issue}

We apply the proposed three-pronged approach to guide cancer screening research to the example of PSA testing (Box 2). This illustrates what types of scientific, social and ethical questions have been investigated to date, although social and ethics research is not often considered as evidence in reviews that guide cancer screening policy and practice. We also suggest questions that could be addressed if the expanded three-dimensional approach to evidence were to be applied to guide new PSA screening research.

The new health technology assessment (HTA) core model for screening technologies developed by the European network for HTA illustrates how an expanded assessment of cancer screening can be operationalised..$^{25}$ This tool identifies questions for assessing the clinical, economic, ethical and social (which they distinguish from organisational and legal) implications of screening technologies. Although the HTA core model does not explore the interactions between the scientific, social and ethical domains identified in this article, the European approach is significantly broader than that adopted by the American Cancer Society, which focuses on scientific evidence. ${ }^{26}$ Unfortunately, there are significant gaps in the empirical work required to answer many of the questions posed in the European HTA model, and when appropriate social and ethics research is lacking, answers are sought from brief consultations and expert opinion. ${ }^{25}$ An expanded social and ethical agenda for cancer screening research would begin to address these gaps in the evidence. This would better support the commencement, provision or 


\section{Scientific, social and ethics research on prostate-specific antigen (PSA) screening, and future research questions}

\section{Domain 1: benefits, harms and costs}

$\begin{array}{ll}\text { Purpose of } & \text { Measure benefits, harms and costs of } \\ \text { investigations } & \text { PSA screening }\end{array}$

Interactions

with other

domains

Ethics can identify new outcomes or distributions of outcomes to measure; social research can explain why PSA screening practice does not always align with evidence-based recommendations

Questions addressed in

available Evidence reviews and recommendations for policy and practice:

research
- What are the net benefits and harms of PSA screening, and what is the evidence-based recommendation for practice? ? $^{3,9,10}$

What is the cost-effectiveness of PSA screening ? ${ }^{1}$ Questions for
further research

\footnotetext{
- What are the broader social and ethical benefits and harms of PSA screening?

- What is the social distribution of harms?

- Are there any conditions under which benefits might outweigh harms?

- Is PSA testing cost-effective?
}

\section{Domain 2: social processes}

Describe the way that PSA screening is provided and communicated about, and explain how it came to be that way

Evidence of benefits, harms and costs can identify unanticipated effects that require social explanations; ethical frameworks can suggest research questions for

\section{Behaviour of physicians and patients:}

Do trials and United States Preventive Services Task Force recommendations have some impact on PSA testing ? $^{12}$

Do physicians influence the likelihood of patients being tested, and what predicts the likelihood of physicians recommending PSA testing ? $^{13}$

What advice do physicians give patients about PSA testing ? $^{14}$

How do men respond to physician advice and why? ${ }^{15}$

Public understandings and communications:

- How do consumers understand the benefits and harms of PSA screening, and what is the impact on screening ? ${ }^{16}$

How do consumers respond to media reporting about PSA testing ? $^{18}$ social research

How do the media report on PSA testing? ${ }^{17}$

\section{Domain 3: ethics}

Guide deliberation regarding the right policy and practice response, and formulate good reasons for those conclusions

Ethical reasoning relies on evidence of benefits, harms and costs; ethical reasoning will be improved by understanding the social context, social structures and processes

\section{Ethical evaluations of PSA screening:}

What are important limitations and gaps in the traditional screening evaluation criteria? ${ }^{7}$ Under what circumstances it is ethical to provide individuals with screening tests that are not recommended at population level ? ${ }^{19}$

How does consent apply to the sons of men with diagnosed prostate cancer with no clinical significance? ${ }^{20}$

Empirical findings with ethical implications for action: is it possible to produce better-informed decisions using community-based interventions ${ }^{2}$ or individual, online decision aids? ${ }^{22}$

How does PSA screening occur? Why does it occur that way?

- How has PSA screening come to be a solution for the problem of prostate cancer?

- What drives testing in men? What are the supplyside and demand-side drivers for testing against the evidence? ${ }^{24}$

- What is the experience of men who have different screening outcomes? ${ }^{1}$

- How is PSA screening used in different jurisdictions? If this varies, how can we explain the variation?

- What do clinicians consider their moral obligations to be in relation to PSA testing?
Ethical implications of questions posed in domain 1: is cancer screening necessary and proportional to the problem, and what is the opportunity cost? ?,2,23 $^{2}$

Can PSA screening be ethically justified? If so, how? If not, why not?

- What do stakeholders value about PSA testing?

- What harms and benefits, beyond morbidity and mortality, should be included in evaluation of PSA testing? Why?

- Are men coerced into PSA testing?

- Are the burdens of PSA testing inequitably distributed?

- Is PSA policy accountable and transparent?

- Can we justify being paternalistic (restricting access to PSA even when men want it)? discontinuation of screening, inform public communication about screening, and assist citizens' decisions about screening. As we move towards the second century of cancer screening, we need to ensure accountability to the citizens whose lives are changed, for better and for worse, by cancer screening programs. We believe the approach proposed is necessary to ensure such accountability.

Acknowledgements: The Screening and Diagnostic Test Evaluation Program is funded by National Health and Medical Research Council (NHMRC) program grants 402764 and 633033. This work was also supported by NHMRC project grant 1023791. Stacy Carter is supported by an NHMRC Career Development Fellowship (1032963).

Competing interests: No relevant disclosures.

Provenance: Not commissioned; externally peer reviewed.

1 Harris R, Sawaya GF, Moyer VA, Calonge N. Reconsidering the criteria for evaluating proposed screening programs: reflections from 4 current and former members of the US Preventive services task force Epidemiol Rev 2011; 33: 20-35.

2 Fletcher SW. Breast cancer screening: a 35-year perspective. Epidemiol Rev 2011; 33: 165-175.

3 Brett AS, Ablin RJ. Prostate-cancer screening - what the US Preventive Services Task Force left out. N Engl J Med 2011; 365: 1949-1951.

4 Roder DM, Olver IN. Do the benefits of screening mammography outweigh the harms of overdiagnosis and unnecessary treatment?-Yes [Opposing views]. Med J Aust 2012; 196: 16.
5 Bell RJ, Burton RC. Do the benefits of screening mammography outweigh the harms of overdiagnosis and unnecessary treatment?-No [Opposing views] Med J Aust 2012; 196: 17.

6 Eddy DM. Clinical decision making: from theory to practice. A collection of essays from the Journal of the American Medical Associaton. Sudbury: Jones and Bartlett, 1996.

7 Holland S. Public health ethics. Cambridge: Polity, 2007.

8 Daniels N, Sabin JE. Setting limits fairly: learning to share resources for health. 2nd ed. Oxford: Oxford University Press, 2008.

9 US Preventive Services Task Force. Screening for prostate cancer. 2011 http://www.uspreventiveservicestaskforce.org/uspstf/uspsprca.htm (accessed Oct 2011).

10 Chou R, Croswell JM, Dana T, et al. Screening for prostate cancer: a review of the evidence for the US Preventive Services Task Force. Ann Intern Med 2011; 155: 762-771.

11 Imamura T, Yasunaga H. Economic evaluation of prostate cancer screening with prostate-specific antigen. Int J Urol 2008; 15: 285-288.

12 Zeliadt SB, Hoffman RM, Etzioni R, et al. Influence of publication of US and European prostate cancer screening trials on PSA testing practices. J Natl Cancer Inst 2011; 103: 520-523.

13 Linder SK, Hawley ST, Cooper CP, et al. Primary care physicians' reported use of pre-screening discussions for prostate cancer screening: a cross-sectional survey. BMC Fam Pract 2009; 10: 19.

14 Clements A, Watson E, Rai T, et al. The PSA testing dilemma: GPs' reports of consultations with asymptomatic men: a qualitative study. BMC Fam Pract 2007; 8: 35. 
15 Rai T, Clements A, Bukach C, et al. What influences men's decision to have a prostate-specific antigen test? A qualitative study. Fam Pract 2007; 24: 365-371.

16 Gigerenzer G, Mata J, Frank R. Public knowledge of benefits of breast and prostate cancer screening in Europe. J Natl Cancer Inst 2009; 101: 1216-1220.

17 MacKenzie R, Chapman S, Barratt A, Holding S. "The news is [not] all good": misrepresentations and inaccuracies in Australian news media reports on prostate cancer screening. Med J Aust 2007; 187: 507-510.

18 Dixon H, Scully M, Wakefield M, Murphy M. The prostate cancer screening debate: public reaction to medical controversy in the media. Public Underst Sci 2009; 18: 115-128.

19 Burger IM, Kass NE. Screening in the dark: ethical considerations of providing screening tests to individuals when evidence is insufficient to support screening populations. Am J Bioeth 2009; 9: 3-14.

20 Justman S. Uninformed consent: mass screening for prostate cancer. Bioethics 2012; 26: 143-148
21 Driscoll DL, Rupert DJ, Golin CE, et al. Promoting prostate-specific antigen informed decision-making. Evaluating two community-level interventions. Am J Prev Med 2008; 35: 87-94.

22 Evans R, Joseph-Williams N, Edwards A, et al. Supporting informed decision making for prostate specific antigen (PSA) testing on the web: an online randomized controlled trial. J Med Internet Res 2010; 12: e27.

23 Harris R. Overview of screening: where we are and where we may be headed. Epidemiol Rev 2011; 33: 1-6.

24 Willis $E$. The prostatic imperative and the social relations of medical technology. Int J Technol Assess Health Care 1997; 13: 602-612.

25 European Network for Health Technology Assessment (EUnetHTA). HTA Core Model for screening technologies. First public draft September 2011. https://webgate.ec.europa.eu/sanco/heidi/images/2/26/2012-04_FI_WEB screening_model_version_110727.pdf (accessed Mar 2012).

26 Brawley O, Byers T, Chen A, et al. New American Cancer Society process for creating trustworthy cancer screening guidelines. JAMA 2011; 306: 2495-2499.

\section{Stamps of greatness}

\section{Leopold Auenbrugger (1772-1809)}

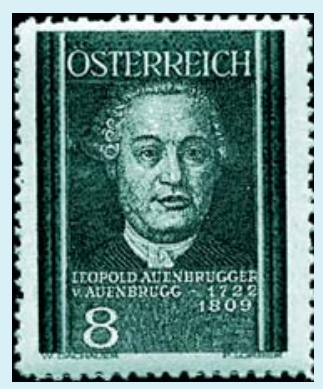

A native of Graz, Austria,

Auenbrugger was born on 19

November 1722 and studied medicine

at the University of Vienna under

Gerard van Swieten. After graduating

in 1751, he became physician-in-chief

of the Heiligen Geist Spital where he

made his most important contribution

to medicine - the use of percussion in the diagnosis of chest diseases.

Auenbrugger had noticed, while

growing up, that the wine levels in wine casks could be measured by listening to the sounds made by tapping the casks. His observations on the use of percussion as a diagnostic technique, after 7 years of study, were published in 1761 in a booklet, Inventum novum, which, however, remained unnoticed.

In fact, his contemporaries ridiculed his ideas on percussion - a procedure now taken for granted, and his discovery lapsed into oblivion until it was rediscovered and revived by

Napoleon's favourite physician, Jean-Nicolas Corvisart (17551821) in 1808.

Auenbrugger's original work had been translated by Rosiere de la Chassagne in 1770 but this work had also largely been ignored by the medical profession. Corvisart published his translation of the work in 1808, which finally helped to popularise the use of percussion as a legitimate diagnostic technique.

Auenbrugger was a man of many accomplishments and even wrote a libretto for Salieri's opera, The chimney-sweep, which was produced at the court of the Empress Maria Theresa of Austria. Eponymically, he is remembered by Auenbrugger's sign, or the bulging of the epigastric region in diffuse pericardial effusion.

Auenbrugger died in Vienna on 18 May 1809, about a year after the reintroduction of his method of chest percussion. Postally he was honoured by Austria in 1937 as one of the great Austrian physicians of the Old Vienna School.

\section{Karl Ferdinand Ritter von Arlt (1812-1887)}

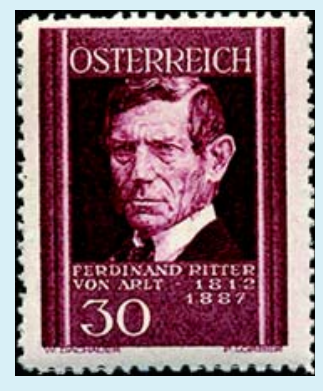

VON ARLT, the son of a blacksmith, was born in Ober-Graupen, a village near Teplitz, then in Austrian Bohemia, on 18 April 1812. He studied medicine at the Karls University of Prague and graduated in 1839.

He was primarily interested in the diseases of the eye, and wrote many articles and books on the subject. He also wrote extensively on the medicolegal aspects of eye injuries and his fame spread rapidly over Europe.

Von Arlt was appointed a professor of ophthalmology, first in Prague (1849-1856) and then in Vienna (1856-1883). He did some original research into the causes of myopia and amblyopia, and was the first to describe what became known as Arlt's sinus of the lachrymal conducting system. An inspiring teacher and prolific writer, he had a big impact on the development of ophthalmology at this important stage of its history.

His work on clinical ophthalmology (Die krankheiten des auges, 1851) long served as a textbook on the topic, while his contribution to the surgical section of the first edition of the Graefe-Saemisch handbuch (1874) played a similar role in the development of ophthalmic surgery.

He persuaded Albrecht Von Graefe to specialise in ophthalmology — von Graefe, along with Hermann von Helmholtz and Franciscus Donders, is one of the three "founding fathers" of the discipline. After von Graefe's death in 1870, von Arlt became the co-editor (with Donders) of von Graefe's Archiv für ophthalmologie (1870-1886). Eponymically he is remembered, among other things, by the Arlt operation for trichiasis.

Von Arlt died on 7 August 1887 and was postally honoured by Austria in 1937 as one great 19th century Austrian physicians. 